BNL- 112024-2016-JA

\title{
International Outdoor Experiments and Models for Outdoor Radiological Dispersal Devices
}

\author{
Daniel J. Blumenthal, Stephen V. Musolino
}

Submitted to the Health Physics Journal

January 2016

Department of Nonproliferation and National Security

Brookhaven National Laboratory

\section{U.S. Department of Energy USDOE National Nuclear Security Administration (NNSA), Office of Emergency Response}

Notice: This manuscript has been co-authored by employees of Brookhaven Science Associates, LLC under Contract No. DE-SC0012704 with the U.S. Department of Energy. The publisher by accepting the manuscript for publication acknowledges that the United States Government retains a non-exclusive, paid-up, irrevocable, world-wide license to publish or reproduce the published form of this manuscript, or allow others to do so, for United States Government purposes. 


\section{DISCLAIMER}

This report was prepared as an account of work sponsored by an agency of the United States Government. Neither the United States Government nor any agency thereof, nor any of their employees, nor any of their contractors, subcontractors, or their employees, makes any warranty, express or implied, or assumes any legal liability or responsibility for the accuracy, completeness, or any third party's use or the results of such use of any information, apparatus, product, or process disclosed, or represents that its use would not infringe privately owned rights. Reference herein to any specific commercial product, process, or service by trade name, trademark, manufacturer, or otherwise, does not necessarily constitute or imply its endorsement, recommendation, or favoring by the United States Government or any agency thereof or its contractors or subcontractors. The views and opinions of authors expressed herein do not necessarily state or reflect those of the United States Government or any agency thereof. 
International Outdoor Experiments and Models for Outdoor Radiological Dispersal Devices Daniel J. Blumenthal and Stephen V. Musolino

With the advent of nuclear reactors and the technology to produce radioactive materials in large quantities, concern arose about the use of radioactivity as a poison in warfare, and hence, consideration was given to defensive measures (Smyth 1945). Approximately forty years later, the interest in the environmental- and health effects caused by a deliberate dispersal was renewed, but this time, from the perspective of a malevolent act of radiological terrorism in an urban area. For many years there has been international collaboration in scientific research to understand the range of effects that might result from a device that could be constructed by a sub-national group. Scientists from government laboratories in Australia, Canada, the United Kingdom, and the United States collectively have conducted a myriad of experiments to understand and detail the phenomenology of an explosive radiological dispersal device.

This special issue details a large body of important results from trials that have generated comprehensive measurements of fireball physics, dynamic measurements of the progression of the plume, and have sampled the particulate- and aerosol-components of the plume, and the ground deposition of radioactive material. These experiments were carried out with an unprecedented amount of instrumentation and multiple measurement strategies, leading to a large, sound body of scientific data. Several significant outcomes emerged from the recent studies in Canada. Most importantly, these experiments reinforce with a large volume of data that there is high confidence in the advice that the United States government is giving to stateand local- agencies on how to protect the responders and the public from the radiological environment that will prevail post detonation (Harper and Musolino 2006, Harper et al 2007, 
NCRP 2010, Musolino et al 2013). ${ }^{1}$ These data also can be used to validate pre- and postdetonation modeling of the fate of the radioactive material in the fireball, and down-wind in the environment.

State-of-the-art models were used to design the experiments and the measurement strategies so to predict the fate of the radioactive material, measure its actual dispersal and deposition, and then to compare prediction and phenomenology. The results of the trials helped to resolve the difficulties of modeling the near-field effects from explosive scenarios. Thus, the trials were unprecedented with respect to the number and the types of high-fidelity real-time measurements and passive ones that were conducted simultaneously at the point of detonation, in the near field, and in the far field (Green et al 201?).:

The airborne concentrations of material in the resulting plume were determined by the following measurements:

- The integrated concentration of airborne activity from fixed high-volume air samplers,

- The concentration of airborne mass by real-time remote sensing with Light Detection And Ranging (LIDAR), and

- The time-resolved gamma dose rate and integrated dose due to cloudshine, using a large array of in-situ gamma detectors.

The material deposited on the ground by ballistic particles and aerosol was determined from the following measurements:

- The concentration of activity, from deposition-filter samples and in-situ handheld beta surveys, and,

- The gamma dose-rate from groundshine, from in-situ fixed-point gamma- detectors, as well as from both airborne- and vehicle-borne gamma-survey instruments.

\footnotetext{
${ }^{1}$ Currently the U. S. Department of Homeland Security Science and Technology Directorate is conducting a project in three cities to launch the implementation of a tactical response plan for the first 100 minutes after the detonation of a radiological dispersal device.
} 
The data collected during the trials provide insights and were applicable to extend the body of knowledge in six topical areas:

- Field testing of measurement- and survey-techniques, including intercomparisons, data-sharing, and data-fusion,

- Cross-comparison of various measurement techniques and evaluation of their cost/benefit for decision making,

- Optimization of the response,

- Forensic investigations,

- Improving understanding of the post -detonation behavior of different source materials, and modeling their associated dispersion behavior,

Amongst other conclusions that can be made from the wealth of data already generated from these trials, insights have been gained into future applications, such as improving the connection between the models and early-consequence management advice, and using models to appropriately place the detectors. Overall, the international scientific community has made great strides in designing experiments to clarify understand the underlying physics, improve the models, and give sound advice that is not excessively conservative to the responders, planners, and decision-makers so that they are aware of the realistic consequences and the boundaries of hazards, large and small, that may be encountered during a radiological incident. The net result is coherent, achievable guidance for assuring the health and safety of the public responders; facilitating lifesaving and rescue without delay, optimizing the ability to preplan to shelter the correct populations, and lowering the risk from evacuation. By mounting a prompt, coherent response during the first 100 minutes of a radiological incident, the confidence of the public can 
be maintained, panic can be avoided, and an indirect savings achieved in lives saved and costs of recovery.

\section{Research Needs}

The experimental and modeling communities continue to contribute to the evolution of , and improvement to the responders' guidance and to assessments to expedite early and accurate recommendations for protective actions. The measurements, such as those in the trials, provide significant empirical data from the standpoint of operational measurements, and inputs to models and forensics. Future trials can contribute to reducing uncertainties in predicting the fate of the radioactivity over a wider range of materials and different device, designs, and strengthen a response and the planning for a response. 


\section{References}

Green AR, Erhardt L, Duke MJM, Lebel L, Quayle D, Jones T, and White D. Overview of the full-scale radiological dispersal device field trials. Health Phys 110:401-402; 2016.

Harper FT, Musolino SV, and Wente WB. Realistic radiological dispersal device hazard boundaries and ramifications for early consequence management decisions. Health Phys 93:116; 2007.

Musolino SV, and Harper FT. Emergency response guidance for the first 48 hours after the outdoor detonation of an explosive radiological dispersal device. Health Phys 90:377-385; 2006.

Musolino SV, Harper FT, Buddemeier, B, Brown, M, and Schlueck, R. Updated emergency response guidance for the first 48 hours after the outdoor detonation of an explosive radiological dispersal device. Health Phys 105:65-73; 2013.

National Council on Radiation Protection and Measurements. Responding to a radiological or nuclear terrorism incident: a guide for decision makers. Bethesda, MD: NCRP; Report 165; 2010.

Smyth, HD. A general account of the development of methods of using atomic energy for military purposes under the auspices of theUnited States government 1940 - 1945, US Government Printing Office, 1945. 